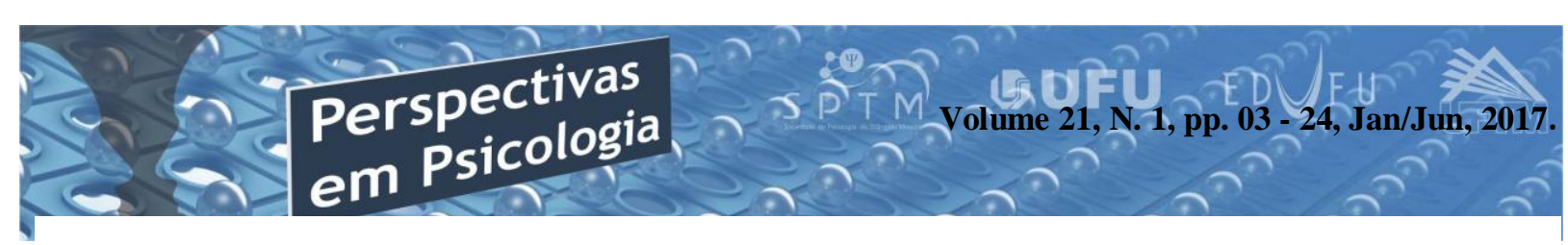

\title{
REFLEXÕES ACERCA DA TEORIA DA AGRESSÃO NA GESTALT- TERAPIA: UMA REVISÃO DA LITERATURA
}

\author{
Thauana Santos de Araújo \\ Adriano Furtado Holanda \\ (Universidade Federal do Paraná - UFPR)
}

\begin{abstract}
Resumo
O trabalho visa o estudo da teoria da agressão na Gestalt-Terapia, buscando sua compreensão a partir da literatura brasileira e estadunidense. Tema central nos princípios da abordagem gestáltica, a noção foi criticada, em torno da confusão feita por Perls a respeito da relação entre as duas formas de agressão que expõe: agressão dental e agressão no sentido de hostilidade. De modo geral, a maioria dos comentadores entende o papel da agressão enquanto função biológica e enquanto contato, frisando seu papel positivo. Evidenciou-se que, na literatura estrangeira, os estudos se desviam mais para o exame da agressão hostil e a análise da positividade e da negatividade desta, ao passo que a agressão dental recebe pouca atenção.
\end{abstract}

Palavras-chave: Gestalt-terapia; Agressão; Revisão de Literatura.

\section{Abstract \\ Reflections on the Theory of Aggression in Gestalt therapy: a literature review}

The work aims at the study of the theory of aggression in Gestalt-Therapy, seeking its understanding from the Brazilian and American literature. A central theme in the principles of the gestalt approach, the notion was criticized, around the confusion made by Perls regarding the relation between the two forms of aggression that exposes: dental aggression and aggression in the sense of hostility. In general, most commentators understand the role of aggression as a biological function and as a contact, stressing its positive role. It has been shown that, in the foreign literature, the studies are more diverted to the examination of the hostile aggression and the analysis of the positivity and the negativity of this one, whereas the dental aggression receives little attention.

Keywords: Gestalt-therapy; Aggression; Revision of Literature.

\section{Introdução}

O conceito de agressão, no

contexto da Gestalt-terapia (GT), embora tenha contornos de centralidade particularmente nos seus primórdios (Perls, 1942/2002) - tem sido pouco trabalhado, ou mesmo esquecido e negligenciado pela 
maior parte dos gestaltistas, bastando para tal observar quão poucas referências encontramos na literatura (Holanda, 2005; Staemmler, 2009).

Desde o nascimento da GT, sua inserção na academia foi dificultada em prol da primazia da prática de vivências, no bojo de um discurso anti-intelectualista, que acabou por enfraquecer a abordagem (Perls, 1992/1994). É na esteira dessa perspectiva de resgate da fundamentação teórico-filosófica que a presente pesquisa tem lugar. Assim, esse conceito basal da agressão, que fundamentou a primeira obra de Perls (1942/2002) - ainda psicanalista na época -, será objeto de estudo deste trabalho.

No caso do Brasil, destaca-se a significativa carência de estudos criteriosos e críticos sobre o tema para além da mera reprodução da teoria, diferentemente do observado nos EUA, em que, ainda que também não tenha havido grande interesse pelo assunto, a repercussão das críticas à teoria direcionou as discussões para novos estudos, o que pode ampliar horizontes, fomentar uma revisão teórica e desenvolvimentos e ensejar utilidade prática aos novos achados.

A teoria da agressão é um marco epistemológico na GT, e se liga a outros conceitos que ganham continuidade nesta abordagem, enquanto a "agressão" segue marginalizada. Dessa forma, um estudo dessa natureza mostra-se importante para a comunidade gestáltica brasileira, que vem buscando resgatar a fundamentação teórica da GT. Helou (2013; 2015) enfatiza a importância de se retomar temas como o da agressão, da fome e da defesa na contemporaneidade, a fim de se reintroduzir a perspectiva da questão do corpo sob enfoques mais amplos do que os da GT até o momento, embora reconheça a propriedade com que Perls percebeu a relação entre "alimentação e defesa" a partir do corpo, colocando a energia agressiva a serviço de ambas de forma invariável. Além disso, ressalta que temas voltados ao corpo e à alimentação e violência são imperativos na clínica, na atualidade, a exemplo de questões contemporâneas como são os distúrbios alimentares e mesmo a violência contra si e contra outrem, que se apresentam pelo corpo e no corpo.

\section{Posição do Problema}

A agressão, basicamente, é um conceito que emerge dos estudos do casal Perls - Fritz e Laura - sobre as "resistências orais", coração da obra de 1942. Perls (1942/2002) parte dos postulados de Freud sobre a fase oral ${ }^{1}$.

\footnotetext{
${ }^{1}$ As correlações entre a GT e a Psicanálise estão melhor tratadas em Helou (2013, 2015). E as origens do tema "agressão" em suas relações com o pensamento freudiano estão melhor analisadas em
} 
Ancorado em uma visão holística, segundo a qual o organismo é um todo indivisível, Fritz faz uma comparação entre o processo biológico da fome e da alimentação e os processos mentais, o que chama de "metabolismo mental". Inicialmente, analisa a ingestão de alimentos no decorrer do desenvolvimento humano desde a alimentação do embrião até a mastigação completa. Para tanto, discrimina diferentes estágios do desenvolvimento do instinto de fome e seus correlatos psicológicos, classificando-os como: pré-natal (antes do nascimento), pré-dental (amamentação), incisivo (morder) e molar (morder e mastigar). A partir desses estágios, apresenta as resistências orais que irão fundamentar a compreensão de processos mentais não saudáveis, como introjeção, narcisismo e retroflexão.

Este trabalho visou o estudo da teoria da agressão apresentada por Fritz Perls, com ênfase nas discussões que brotaram após seu surgimento no meio gestáltico brasileiro e estrangeiro, ora trabalhando sua teoria, ora abordando suas imprecisões. Algumas das críticas aparecem mais solidamente em Staemmler (2009) e Helou (2013, 2015), que denunciam mais veementemente essas imprecisões. Enquanto Helou (2013, 2015)

Araújo \& Holanda (2016), “As Origens do Conceito de Agressão na Gestalt-terapia: Psicanálise e Clínica” (no prelo). assinala a questionável leitura que Perls faz de Freud com relação ao tema, Staemmler (2009) calca suas críticas nas duas conotações com que agressão aparece nas obras de Perls, quais sejam, a agressão dental (biológica e ligada à assimilação do novo e à discriminação do que serve e do que não serve para si), e a agressão no sentido coloquial do termo, isto é, no sentido de hostilidade. Neste texto, estaremos nos atendo ao debate com respeito às imprecisões conforme apontadas por Staemmler e, também, aos rumos que o tema da agressão tomou na GT brasileira e na GT americana.

$\mathrm{Na}$ busca por publicações em GT sobre a teoria da agressão, em língua portuguesa, observou-se que apenas Pimentel (2005) abordou o assunto de forma mais aprofundada e procurou "testar" a agressão dental em um estudo com crianças de 7 a 10 anos que visou detectar alimentos psicológicos e sociais que dão suporte ao desenvolvimento, por meio de uma pesquisa clínico-qualitativa sobre as relações entre mastigação, alimentação e desenvolvimento social e emocional. Para Staemmler (2009), pesquisador alemão que se ocupou do tema, um dos motivos, talvez, para o desinteresse no tema, é sua exposição confusa nas obras de Perls em relação à agressão dental e à agressão hostil. 
Não foi encontrado nenhum trabalho explicando o porquê desse abandono. Talvez, a onda de "antiintelectualismo" - como apontado por Laura Perls (1988, 1992/1994) - bem como as críticas acerca da não responsabilização dos gestaltistas pela construção de um conhecimento próprio (Faria, 2005; Holanda, 2005), envolvendo a abordagem numa bruma antimecanicista, anti-científica e antipositivista - modelo abraçado pela "psicologia humanista" do século passado - findou por manter tendências românticas e uma abordagem "antiestruturalista", portanto, não teórica, aclimatando essa atmosfera de quase desprezo pelo tema. Mas, mesmo dentro da comunidade brasileira, não encontramos acordo quanto a estas questões conceituais e epistemológicas; Ribeiro (2005), por exemplo, um expoente da abordagem gestáltica no Brasil, é adepto da visão de que a GT não precisa de uma teoria do desenvolvimento da personalidade, lembrando que o conceito da agressão nasceu de uma tentativa de esboçar uma. Outro elemento que pode ter favorecido tal situação é o fato de que o tema da agressão vai "perdendo" força ao longo das obras analisadas aqui, ao contrário dos demais conceitos gestálticos.

Conforme levantamentos sobre as produções de mestrado e doutorado brasileiras em GT, feitos por Holanda e Karwowski (2004) e Holanda (2009), abrangendo o período de 1982 a 2008, aumentou o número de pesquisas de cunho teórico-filosófico na área. Mesmo assim, são poucas as referências que tocam o tema da agressão - como em Fittipaldi (2007) e Helou (2013) -, encontradas em uma verificação, feita em bases de dados abertos como Scielo, PePSIC e BVS, utilizando-se as palavras-chave "agressão e Gestalt", "agressão e Gestalt-terapia" e “agressão e Perls". Com relação às origens do conceito, um único artigo foi encontrado nas mesmas bases de dados utilizando-se as palavras-chave "agressão Gestalt origem" e "Perls e Freud" (MüllerGranzotto \& Müller-Granzotto, 2007). No caso dos trabalhos estadunidenses utilizados, a busca se deu na revista Gestalt Review, com as palavras-chave "aggression Perls". Foram selecionados e examinados os artigos pertinentes ao tema, bem como a obra de Staemmler (2009), que apresenta um estudo do conceito nas obras de Fritz, confrontando tais estudos com pesquisas recentes. Tomou-se conhecimento desta obra também por meio da referida revista. Nesse levantamento, apareceram 29 resultados, dos quais apenas seis se debruçavam diretamente sobre a Teoria de Agressão em si, quais sejam: Smith (2007); Lichtenberg (2012); Skovgaard \& Winther-Jensen (2015); Staemmler \& 
Staemmler (2015); Yontef (2015); Lobb (2015).

Neste estudo, apresentaremos brevemente a teoria da agressão na perspectiva de Fritz Perls como ponto de partida para a discussão de literatura que se pretende travar. Assim, com base no exposto até o momento, este trabalho aponta como problema de pesquisa: qual o papel da noção de agressão para a Gestaltterapia?

\section{Sobre o Tema da Agressão}

2.1. A Teoria da Agressão segundo Fritz Perls

Este tópico tem o condão de apresentar brevemente a teoria da agressão dos Perls com base nas obras Ego, Fome e Agressão: uma revisão da teoria e do método de Freud (Perls, 1942/2002); Gestalt-terapia (Perls, 1951/1997); Escarafunchando Fritz: dentro e fora da lata de lixo (Perls, 1969/1979); A abordagem gestáltica e testemunha ocular da terapia (Perls, 1973/2011); além do texto Moral, Fronteira do Ego e Agressão (Perls, 1975/1977).

No cômputo geral, todas as obras de Perls apresentam as mesmas premissas sobre a teoria da agressão, não havendo alterações em sua essência. A tônica da teoria da agressão está no seu papel de viabilizar a assimilação de material novo a partir do meio e a aprendizagem da discriminação, pelo organismo, do que lhe serve e do que não lhe serve, tanto no nível físico quanto no mental, processos necessários ao crescimento. Por meio da agressão dental, que é um instrumento do instinto de fome, o indivíduo aprenderá a agredir seu alimento, destruindo-o - no sentido de desmembrar em partes para tornar a comida assimilável -, ao que absorverá os nutrientes que lhe servem, os quais passarão a compor seus músculos, órgãos, e assim por diante. Para Perls, esse mesmo processo se dá na esfera psicológica (visão holística): a partir desse exercício inicial com a alimentação, que começa com o nascimento dos dentes, o homem aprenderá, posteriormente, a agredir a vida, a buscar atender suas necessidades, a destruir e mastigar as situações de vida (a que Perls chama de alimentos mentais), passando a fazer suas escolhas. A esse mecanismo, Fritz chamou de "metabolismo mental".

Porém, ao longo de sua fundamentação, Perls traz, simultaneamente, um outro conceito de agressão: o de agressão no sentido de hostilidade, tal qual referida na linguagem cotidiana. Assim, Perls faz uma articulação entre ambos, postulando que a agressão 
dental, quando reprimida ou impedida de funcionar adequadamente de acordo com a necessidade organísmica no local biologicamente correto - isto é, os dentes se transformará em agressão hostil. Dito de outro modo, aquele que não aplicar os dentes na vida a seu favor e a favor de seu organismo como um todo (suas exigências psíquicas, emocionais, corporais, dentre outras) canalizará essa repressão em forma de hostilidades, tais como guerras e crueldades. O problema é que essa relação, e também a forma como Perls expõe seus argumentos, ora sobre uma, ora sobre outra noção de agressão, inúmeras vezes soa confusa no conjunto da sua obra, especialmente nos escritos de 1942 e no de 1951, o que será melhor esclarecido doravante pelos comentadores estrangeiros.

2.2. Repercussões sobre a Noção de Agressão no Brasil e nos EUA

\subsubsection{Na Literatura Brasileira}

Loffredo (1992), Pimentel (2005), Ribeiro (2006), Fittipaldi (2007), MüllerGranzotto e Müller-Granzotto (2007) e Helou (2013; 2015) foram os comentadores encontrados que se dedicaram ao tema da agressão na literatura brasileira, ainda que superficialmente, com exceção de
Pimentel, que aplicou o conceito em um estudo de campo, desenvolvendo a expressão "nutrição psicológica". Loffredo apenas cita brevemente do que se trata o assunto, não muito diferentemente dos demais, que não pesquisam a fundo a teoria. Müller-Granzotto e MüllerGranzotto analisam a questão da força destrutiva e da força unificadora, em Perls, confrontando com Freud. Fittipaldi e Helou vão um pouco mais além: aquela, em seu estudo sobre a paz, analisa sucintamente a agressão negativa e a positiva em Perls; Helou, que empreende um estudo panorâmico da produção teórica de Perls, analisando a influência da psicanálise e de outras teorias sobre o pensamento dele, apresenta, também ligeiramente, a trajetória do conceito, bem como onde estava o pensamento de Perls e o que ele pretendia quando de sua formulação. Já Ribeiro (2006) apenas expõe a definição do conceito. Assim, tanto com relação aos estudos brasileiros quanto aos estrangeiros, optou-se por apresentar mais detidamente apenas aqueles que proporcionam uma discussão mais aprofundada sob novas perspectivas, excluindo-se os que somente expuseram ou reproduziram a teoria e os que tratam de questões epistemológicas, como as possíveis teorias de origem do conceito.

Antes de analisar as referências mais diretas, é importante fazermos ainda 
duas ressalvas. Na obra Dicionário de Gestalt-Terapia, no verbete "agressão", a cargo de Cláudia Ranaldi, a definição se alicerça no artigo intitulado "Moral, Fronteira do Ego e Agressão" (Perls, 1975/1977), escrito por Fritz para o livro de John Stevens. Neste verbete, a ênfase recai sobre a "agressividade saudável" embora citada genericamente como "agressão" - e encarada como uma “(...) função importante para $\mathrm{o}$ crescimento emocional saudável (...)” (Ranaldi, 2014, p. 20). Ainda, na sequência, buscando compreendê-la numa dimensão mais técnica, aponta para a possibilidade da agressão permear a relação terapêutica: "Podemos assim, junto com nosso cliente, mastigar e digerir suas vivências, buscando soluções criativas - e não temerosas diante de suas escolhas e da verdadeira expressão do Ser” (p. 20). A segunda ressalva refere-se ao livro organizado por Frazão \& Fukumitsu (2014), intitulado Gestalt-Terapia. Conceitos Fundamentais - como parte de uma coleção sobre GT, que já conta com quatro volumes, na qual o referido texto aparece como o segundo volume - onde não encontramos capítulo explicitado sobre o tema em tela.

Fittipaldi (2007), em harmonia com Perls e sua compreensão da agressão, sugere que nem a agressividade, nem a força, nem a luta, são equivalentes à violência, pois a agressividade e a força, numa luta, possibilitam a manutenção do conflito, enquanto que a violência acaba por desregular o conflito, já que impede que as partes estabeleçam justiça entre si. A violência não é inerente à natureza humana, mas a agressividade é, posto que diz da combatividade, da capacidade de encarar o outro sem esquiva, da afirmação de si. Para Fittipaldi, essa visão corrobora totalmente a visão gestáltica de agressão enquanto uma função biológica. Assim, o que vale destacar desse estudo é que a nãoviolência pressupõe a capacidade de ser agressivo. Sob essa ótica, uma cultura da paz não requer ausência de agressão ou de conflito, mas sim o bom exercício da agressão com o fim de sanar os conflitos de forma pacífica, e lembra que a GT aduz que todo conflito ativo trabalha a favor da integração do self, de modo que a pacificação precoce dos conflitos é que tem um viés neurótico. Com isso, a comentadora diferencia a paz positiva da paz negativa.

Pimentel (2005) empreendeu um estudo mais aprofundado sobre o tema da agressão em seu livro, incrementando as discussões sobre esse assunto com diversas pesquisas, algumas relativas ao desenvolvimento infantil, além de ter realizado um estudo de campo. A comentadora disserta sobre o 
desenvolvimento emocional e social, tomando-o como um processo que vincula todos os sistemas que compõem o ser humano, na busca de detectar alimentos psicológicos e sociais que dão suporte ao desenvolvimento. As discussões se circunscreveram na interface da psicologia com a odontologia e com a nutrição. Sua compreensão vai ao encontro das teses de Perls. A partir das elaborações deste, Pimentel (2005) formula ideias que procuram alinhavar os processos orgânicos da mastigação e digestão e os processos da nutrição psicológica, chegando à formulação das categorias "metabolização" e "nutrição psicológica" para diferenciar os processos digestivos orgânicos especialmente a mastigação, que é o primeiro ato que principia a digestão alimentar pela utilização dos diferentes tipos de dentes - dos processos psicológicos que trabalham para a configuração do "eu". A categoria "nutrição psicológica", que se concretiza pela metabolização psicológica - a qual formulou com suporte na definição de Piaget - pode ser, para Pimentel, uma colaboração conceitual para se aperfeiçoar a semente plantada por Perls em suas postulações sobre o tema da agressão. Nutrição psicológica designa “o provimento de alimentos afetivos indispensáveis para a formação da autoestima e do autoconceito saudáveis, além da capacidade de reconhecimento do outro" (p. 23).

No sentido concreto, ancorada em pesquisas da odontologia, explica que crianças e adolescentes costumam engolir e deglutir pedaços grandes de alimento, e que seu sistema digestivo é apto a lidar com porções grandes. Sendo assim, considerando essas características, formula a hipótese de que a nutrição psicológica é um processo mais lento do que a nutrição orgânica, que ocorre de forma mais acelerada nos primeiros anos de vida devido a essa capacidade digestiva das crianças e adolescentes. Vale mencionar que essa constatação de que crianças e adolescentes têm condição de digerir grandes pedaços se configura em uma importante discordância da declaração de Perls (1942/2002) de que o estômago é uma fina pele que precisa dos alimentos muito bem liquefeitos desde a mais tenra infância para uma digestão adequada.

Pimentel (2005), com suporte em Piaget, propõe que a nutrição psicológica se atualiza com o tempo, uma vez que a criança não concretiza de forma plena a metabolização psicológica do alimento mental, pois opera, no plano cognitivo, no âmbito sensório-motor de operações concretas, além de razões culturais, educacionais e instrucionais, já que não é orientada para se preparar para exercer sua vontade. Assim, os processos cognitivos de 
abstração se inscrevem na adolescência, fase esta que deve ser compreendida como tangenciada por vivências de uma série de modificações subjetivas corporais e sociais.

Por fim, Ribeiro (2006), similarmente a Perls, define agressividade, agressão e agredir como aspectos da mesma realidade, em mútua participação: "agressividade é um processo humano, inato, que provoca na pessoa uma complexa sensação de expansão, de ir além de si mesma, de correr riscos, de ampliar limites, de terminar o começado. É um instinto a favor da vida (...)" (p. 59). Segue argumentando que agredir é um gesto que visa causar dificuldades a outrem. Considera que, por vezes, é uma resposta; outras vezes, é um impulso com determinado nível de consciência, mas que aparenta um movimento em que uma ou as duas pessoas excedem os limites do convívio normal para atacar ou se defender da outra, podendo ainda ser uma ação da pessoa contra si própria. Acrescenta que, na base da agressão, está um não reconhecimento da relação parte-todo da pessoa, ou seja, da relação pessoaambiente, pois a agressão emerge frente a um sentimento de invasão da própria privacidade, intimidade, singularidade e totalidade. A agressividade, que se encontra na origem tanto do agredir quanto da agressão, "tem algo de existencial, de sentido de vida, na medida em que expressa um momento de autopreservação, uma tentativa de auto-regulação organísmica ou de ajustamento criativo" (p. 60). Ribeiro destaca que falar de agressividade é diferente de se falar de uma pessoa agressiva, uma vez que agressividade tem o escopo de instrumentalizar ou regulamentar a relação entre diferentes, estando, não raras vezes, atrelada à baixa autoestima, desesperança, dentre outros. Para o comentador, adoecese quando se utiliza mal o instinto de agressividade, de modo que alguns bloqueios de contato também são carência de agressividade, ou refletem o uso indevido dela.

\subsubsection{Na Literatura Estrangeira}

A literatura estrangeira analisada aqui, de um modo geral, aprofunda mais o estudo sobre a agressão e apresenta diferentes e inovadoras perspectivas, porém, envereda mais para o estudo da agressão hostil. Smith (2007) se dedica a apontar as semelhanças entre a teoria da agressão de Perls e o pensamento de Nietzsche, argumentando com propriedade e com muitos exemplos, a fim de atribuir a origem dessa teoria ao filósofo. Como o 
foco deste trabalho não é a origem do conceito, esta não será examinada por ora.

Staemmler (2009), em sua obra Aggression, Time, and Understanding: contributions to the evolution of Gestalt Therapy, explica que almeja por mudanças e desenvolvimentos na teoria da agressão na GT que sejam mais adequados do que a teoria original, para alcançar seus objetivos a respeito do questionamento sobre como é possível, enquanto cidadãos, nos educar para a paz (fazendo alusão a um dos ensaios de Laura Perls) e sobre como, enquanto psicoterapeutas, podemos apoiar nossos clientes a descobrir formas pacíficas de lidar com os desafios com os quais a vida os confronta. Acrescenta que seu ponto de vista difere essencialmente daquele dos Perls, apontando críticas à teoria e ao método da agressão; e revela, ainda, que as opiniões críticas que sustenta receberam suporte adicional de pesquisas acadêmicas em Psicologia, dos conhecimentos e estudos de vários aspectos práticos e teóricos da psicologia e espiritualidade budistas. Vale mencionar que o posicionamento budista de Staemmler é um fator capital em toda sua fundamentação, e ele acredita que sua proposta levará a uma revisão da teoria.

Staemmler (2009) não vislumbra a agressão como uma força positiva de vida, e discorda que se deve olhar para o alimento mental do mesmo jeito que se olha para o alimento físico. Ele questiona se Perls tirou tal relação de uma analogia, de um isomorfismo ou da causalidade, e critica a atribuição de um determinado estilo de ser humano a cada estágio do desenvolvimento dental. Assim, comunga da mesma observação de From e Miller (1997) - embora estes últimos tenham comunicado que esta ideia amadurece na obra de 1951: o entendimento de Perls sobre a agressão é intrapsíquico, exclusivamente uma função intrapsíquica, não representa intervenção no mundo, uma emoção expressa ou sentimento experienciado, e que deriva do processo biológico da comida ingerida e da digestão; além disso, Perls coloca o crescimento e bem-estar individual em primeiro lugar, posto que aparentemente para ele sociedade e comunidade eram forças opositoras e opressoras, prejudiciais ao sujeito. Para Staemmler, o que é experienciado nesse contexto é a fome, não irritação, incômodo ou raiva. Ninguém sente tais sentimentos contra a comida e deseja aniquilá-la, de modo que a destruição que ocorre da comida é funcionalmente necessária, não tendo nada a ver com a agressão ou destruição à qual nos referimos todos os dias. Em relação ao material cognitivo vale a mesma lógica: as pessoas podem pensar sobre muitos assuntos sem que estejam acompanhados de uma experiência agressiva. Tanto na 
fala coloquial como na científica, alega o comentador que agressão geralmente denota um ataque ofensivo, associado à raiva.

No entanto, a confusão, elucida Staemmler, vem do fato de o próprio Perls se referir muitas vezes ao termo "agressão" com o mesmo significado presente na linguagem cotidiana e na científica, na obra de 1942. Portanto, a agressão a que Perls se remete não tem nada a ver com a compreensão costumeira que se tem de agressão. É, antes, uma função do organismo. Assim como Perls acreditava que a atividade da agressão interna é necessária para um metabolismo saudável, ele também entendia que externalizar agressão contra a pessoa responsável pelo sentimento hostil é necessário para manter a saúde psicológica. Staemmler (2009) contesta a noção de que a experiência de raiva ou de sentimentos agressivos colocada como um processo natural seja de fato um processo natural. Isso traduz uma equivocada noção de normalidade. Ademais, uma discussão crítica sobre a noção de catarse até hoje quase não teve lugar. Afora isso, o exame da teoria da agressão dental tem sido esquecido. Quem mais tem cuidado disso, segundo ele, é Petzold $^{2}$. O problema é que os efeitos

2 Refere-se a: Petzold, H. G. (2006). Aggressionsnarrative, Ideologie und Friedensarbeit nocivos da expressão da agressão são bem menos conhecidos do que os efeitos da inibição e repressão dela. De fato, retrofletir agressividade tem consequências sérias, mas não tão pronunciadas quanto as da expressão da raiva.

Nesse momento, parece oportuno relembrar que Perls, tanto no manuscrito de 1942 quanto em sua autobiografia, de 1969, sustenta que a descarga sem sentido e sem direção é insuficiente, pois está se tratando de um processo de maturação do sujeito, e no documento de 1951, Perls, Hefferline e Goodman dão a entender não que encorajam a descarga pura e catártica, mas que não a impedem, não proíbem expressões agressivas em terapia para que o paciente possa se perceber se censurando e se retraindo. Sobre o controle da raiva, Staemmler censura o entendimento dos gestalt-terapeutas que se assentam na teoria paradoxal da mudança para se agarrar à ideia de que o autocontrole arbitrário e o controle deliberado da agressão não são suficientes, pois, para ele, adversativamente, a mudança não é assim passiva e a tentativa de controle não irá levar a alguma patologia. Há várias estratégias que podem ser aplicadas. Quando a hostilidade emerge, ela deve ser

- Integrative Perspektiven. In F.-M. Staemmler \& R. Merten (Eds.), Aggression, Selbstbehauptung, Zivilcourage - Zwischen Destruktivität und engagierter Menschlichkeit (pp. 39-72). Bergisch Gladbach: Edition Humanistische Psychologie. 
ativamente controlada, a pessoa deve interromper sua efetivação. E, com base na Teoria da Avaliação, deve-se também, segundo Staemmler, observar e debater o padrão de avaliação dos clientes sobre situações agressivas, especialmente se tendem a justificar suas respostas agressivas a partir do comportamento do outro.

De acordo com Staemmler, um outro argumento na GT que procura justificar um cunho positivo para a agressão é a invocação de sua etimologia, tal qual se observa em Perls, Hefferline e Goodman (1951/1997), que dizem que agressão, originalmente no latim, significava apenas se aproximar de algo. Ocorre que, para Staemmler, essa transposição do termo se deu de forma incorreta e a-histórica, uma vez que agressão, hoje, denota outro tipo de comportamento. Sobre a metáfora "metabolismo mental" de Perls, Staemmler advoga que ela é velha para as perspectivas atuais com base em vastas evidências de novas pesquisas em psicologia do desenvolvimento, da emoção e da cognição. Alude que, no tempo de Fritz, já havia conhecimento disponível, como por exemplo os providos pela Psicologia da Gestalt, que se opunham às suas considerações. Além disso, Staemmler relata que tal metáfora não é baseada numa observação de crianças, já que nem Freud nem Fritz alimentaram algum infante na vida. Ademais, enquanto a digestão física é involuntária e não consciente, o processamento do conteúdo mental é sempre conectado com uma direção voluntária de atenção e com pensamento consciente, o que é verdadeiro a despeito de a maioria dos processos cognitivos não se darem conscientemente. Não se pode atribuir reflexões mentais aos órgãos digestivos, e processos mentais são dialógicos, diferentemente da digestão.

Faz-se oportuna mais uma consideração nesse ponto: embora Perls nunca tenha alimentado alguma criança para testar sua teoria, Laura Perls o fez, e é uma das responsáveis pela origem dessa teoria, conforme conta em uma entrevista feita por Bernard (1986) e em Laura Perls (1988). Staemmler (2009) ainda questiona que tipo de crescimento exatamente a agressão propicia. Denuncia que uma definição qualitativa de crescimento não é encontrada nos escritos de Perls. Sobre esse entendimento de Staemmler, abre-se outro parêntese: Perls, Hefferline e Goodman (1951/1997) definem crescimento como: "aumento de tamanho, restauração, procriação, rejuvenescimento, recriação, assimilação, aprendizagem, memória, hábito, imitação, identificação" (p. 225). Todos corolários do ajustamento criativo. A alimentação, que transforma o não semelhante em semelhante, é similar à 
aprendizagem quando esta é digerida e assimilada, e não engolida inteira. Ela não poderá ser usada diferentemente de nossa muscularidade, por exemplo. Quem cresce é o organismo, e não o self. Desse modo, Fritz não se refere somente a crescimento quantitativo.

Na sequência, Staemmler (2009) explica a necessidade de se distinguir as categorias motivacionais do ser humano como, por exemplo, distinguir reação de aversão por antagonismo ou retirada (= agressão) da necessidade de exploração e afirmação, pois, para a psicologia motivacional (respaldada na neurociência) e do desenvolvimento, mais do que uma questão de diferenciação terminológica, a necessidade de afirmação visa colocar as próprias necessidades e desejos na frente, mas não pretende prejudicar ninguém. Já a motivação por trás da agressão tem essa meta. Segundo Staemmler, os Perls reconhecem tais motivações, mas as colocam na mesma categoria "agressão". Com isso, conclui que não se pode mais justificar qualquer apoio à exposição de raiva dos clientes, ainda que em fantasia, especialmente em clientes que já são agressivos. A cada expressão de raiva, o padrão neuronal agressivo é fortalecido, o que tem sido confirmado em pesquisas psicológicas sobre a agressão.
O melhor método então seria primeiro identificar quais fatores normalmente fomentam raiva e ódio, a origem do sentimento hostil. Nesse sentido, a inferência do comentador é que, no contexto clínico, se promova o fortalecimento da resiliência e da autoconfiança, reduzindo as chances de se utilizar da agressão como recurso. A verdadeira autoconfiança carece de defensividade. O melhor é claramente discernir o sistema motivacional respectivo. Nesse trecho, também encontramos correspondência com Perls, Hefferline e Goodman (1951/1997) e Perls (1975/1977), que deduzem algo parecido ao afirmar que, na vida real, ao obter uma resposta leve de alguém que uma pessoa acabou de insultar, esta cai em si.

Por fim, Staemmler conclui que a teoria da agressão na GT clássica, tal qual proposta por Perls, não passou no teste de escrutínio. É inconsistente e terminologicamente confusa. Sua base é uma metáfora conceitual enganosa ("metabolismo mental"). Em contraste com a tradição em GT, o comentador apoia que falar de (grifo dele) raiva pode ser um instrumento de redução da prontidão para raiva e agressão. Quanto à expressão catártica, não só foi refutada como provado que eleva a agressão subsequente. 
Em artigo que discute e contesta o posicionamento de Staemmler de que a raiva é somente destrutiva e de que não há agressão positiva, Skovgaard e WintherJensen (2015) discordam e acrescentam que há um potencial de cura na raiva consciente. Porém, consideram que há um problema de ideologia e definição no texto de Staemmler, manifesto no fato de demonstrar desgosto por todas as formas de raiva e especificamente por uma falta de distinção entre diferentes expressões de agressão. Com isso, a raiva cotidiana e a raiva patológica acabam por parecer do mesmo tipo. Consideram, como Winnicott, que expressões concretas de raiva podem auxiliar as crianças a se ajustarem à realidade e a abandonarem ideias mágicas de aniquilação do mundo, e apontam uma pesquisa em que, se entendida como contato, a agressividade da criança manifestada contra pais pouco atenciosos tende a desaparecer na maturidade (comportamento descrito como "agressão proativa").

Skovgaard e Winther-Jensen (2015) relatam que têm a impressão de que Staemmler pensa a raiva como um fenômeno geralmente prejudicial que sempre deve ser transformado em outra coisa. A raiva seria parte da natureza humana, e ressentimento e acting-out (encenação, "por para fora") não são iguais à raiva. Esta, portanto, pode ser não só construtiva como também necessária ao desenvolvimento mental. A raiva é relacional, e pode representar uma forma real de contatar a realidade, bem como um meio de contato, como apontam algumas pesquisas. Assim, definem raiva, concordando com Winnicott, como uma reação à frustração, e como fonte de energia pessoal. Já a agressão deve ser entendida, para elas, em sentido amplo, ou seja, como limite, integridade, foco, iniciativa e empreendimento. Esse é o sentido de agressão construtiva que elas aplicam em termos de personalidade. Skovgaard e Winther-Jensen (2015) são da opinião de que a raiva pode ser empoderadora e útil em um diálogo. Neste caso, seria uma raiva consciente. A raiva inconsciente, raiva confusa, que é a expressa de maneira mais destrutiva. Apontam alguns estudos que corroboram nessa matéria. Na terapia, um cliente pode testar diferentes expressões de raiva e experienciar quando e como isso é suficientemente flexível e afiado. Assim, fundindo controle e abertura, almeja-se que o cliente obtenha controle de sua raiva pelo reconhecimento dela e escolha a expressão adequada para ela.

Staemmler e Staemmler (2015), em réplica, basicamente retomam o já apontado na obra que fora criticada por Skovgaard e Winther-Jensen (2015), não considerando útil subsumir divergentes 
fenômenos sob a mesma excessivamente ampla categoria "agressão". Dessa forma, os estudiosos que ainda mantêm esse posicionamento terão que rever e reestabelecer a diferenciação de termos e categorias, utilizando-se de diferentes palavras, e deixar de usar expressões como "agressão inclusiva" versus "agressão exclusiva" (em menção a Lichtenberg, 2012).

Após ler o livro de Staemmler (2009) e o artigo de Skovgaard e WintherJensen (2015), Yontef (2015) afirma que, sobre o modo como Perls trabalha com o termo "agressão" em sua obra - sem distinguir entre a agressão enquanto construção e enquanto destruição hostil -, “a eventual percepção de que há uma energia comum que o organismo utiliza em todos os níveis, desde o biológico ao ajustamento criativo a nível global pode ser útil, se explicada. Mas, da forma como está, é simplista, confusa e enganosa" (p. 1). Um debate em GT sobre raiva e comportamento em que há raiva ("comportamento agressivo") torna-se colorido pelo uso contraditório do vocábulo agressão e por questões simplistas e binárias, tais como: será que é destrutivo? A raiva, para ele, é um afeto que pode ser experienciado com uma ampla gama de níveis de conscientização e que pode ser expresso em uma variedade de comportamentos, e é relacional. $\mathrm{Na}$ prática clínica, Yontef acredita ser muito importante diferenciar raiva e fúria. "Fúria" sempre carrega outros componentes emocionais além da raiva, como sentimentos de impotência, vergonha, humilhação, medo ou desespero. Todavia, a raiva simples no contato pode levar à reconciliação ou a tristeza e equanimidade. Fúria, raiva e ódio não são a mesma coisa.

Yontef (2015) concorda com Staemmler (2009) no tocante à catarse, e diz que experiências catárticas têm utilidade limitada. Mas aponta que alguns ajustamentos requerem imposições ao ambiente pelo indivíduo. Isso é agressão ou assertividade? Saudável ou destrutivo? Depende, responde ele. O que é necessário na situação imediata? Há modos mais efetivos de atingir a meta desejada? O custo é mais oneroso do que os efeitos benéficos para o indivíduo e para o ambiente? Para ele, a questão não é se a raiva é inerentemente destrutiva, e sim quão bem uma pessoa está consciente de sua raiva e comportamentos que estão surgindo a partir dela. Quanto a estar consciente da raiva, tanto Skovgaard e Winther-Jensen (2015), quanto Staemmler (2009) e Yontef (2015) estão de acordo. Yontef assinala que, no trabalho clínico, um sentimento precisa ser entendido, 
experimentado, aceito e tolerado ao invés de julgado como destrutivo ou útil. É necessário saber como a raiva é experienciada e libertar a experiência da obrigação de mudança para algo novo a surgir e se desenvolver. Com a consciência suficientemente ampla e profunda, sentir a raiva pode levar à paz ou pode significar o comportamento assertivo. A teoria da terapia da Gestalt iria melhorar com o apoio de melhorias semânticas.

Outro trabalho interessante sobre o tema é o de Lichtenberg (2012), que advoga a favor do que chama de "agressão inclusiva e exclusiva", defendendo a ideia de que, se o homem puder lidar com a agressão na vida cotidiana para promover modos de ser agressivo que constroem comunidade e para bem gerir os modos que são destrutivos do bem-estar comum, poderá mudar a forma como o mundo funciona e contribuir para um futuro mais pacífico. O comentador informa que, dentro dos campos da GT, da psicanálise e da psicologia social existem concepções concorrentes de agressão, e que seu objetivo é observar as alternativas e tentar apoiar a perspectiva provocante introduzida pelo texto fundador da GT, visando atualizar a visão relacional de agressão implícita no texto original, que careceu de explicação adequada.

Lichtenberg (2012) toma como pano de fundo os estudos de Staemmler e de Jessica Benjamin, sobre psicanálise relacional (esta apresentaria uma visão que se coadunaria com a da GT clássica). Para Lichtenberg, a agressão é mal-entendida no uso do senso comum porque é sempre associada a guerras entre nações e dentro delas, enquanto que, para ele, não há relação humana sem agressão uma vez que não há relacionamentos sem pessoas energeticamente se apresentando a outras. $\mathrm{O}$ esforço na relação e na interação com outros e para com os outros é a essência da agressão. Ao explorar o mérito da agressão em seus aspectos inclusivos e exclusivos, distingue a agressão positiva da negativa. Para tanto, diferencia orientações que partem de uma Gestalt saudável ou de uma Gestalt neurótica. Assim, agressão significa uma coisa dentro de uma orientação inclusiva e algo completamente diferente em uma orientação exclusiva. Nessa direção, Lichtenberg cita outro trabalho seu, de 1988, em que desenvolveu o que chamou de "dispositivos". No extremo positivo ideal estaria uma disposição rotulada de "expectativa confiante"; no extremo negativo, estaria uma disposição referida como "antecipação ambivalente essencial". Assim, as pessoas poderim ser "alocadas" nesse continuum, de acordo com seu jeito típico de ser. Admite ter colocado tais dispositivos dentro de uma tradição psicanalítica. Com isso, ele delineou 
algumas definições de agressão nas duas orientações ou disposições: uma agressão inclusiva, abalizada na confiança de que nossas necessidades serão cumpridas; e uma agressão exclusiva, respaldada na expectativa de que todos os ganhos têm custos. Em ambos os casos, a agressão é um self enérgico, vigoroso, assertivo ou protetor nas relações humanas. É a energia de ação.

$\mathrm{Na}$ sua forma inclusiva, agressão aparece no processo de se engajar de um modo conectado e mantém o envolvimento com aqueles que são objeto da nossa atenção. $\mathrm{Na}$ forma exclusiva, agressão aparece como a energia nos processos que diminuem ou negam o outro na relação, ou, alternativamente, diminui ou nega a si mesmo no relacionamento. A ambiguidade da agressão, assim, é que ela pode unir ou dividir, incluir ou excluir, igualar ou se opor à igualdade, dependendo se seu sustentáculo é uma Gestalt saudável ou neurótica (Lichtenberg, 2012). Na sua forma inclusiva, ser agressivo é energeticamente promover um "Eu" e um "Tu" distintos no relacionamento. O excesso de energia usado em dominar ou negar os outros é melhor visto como uma indicação de sentimentos de vulnerabilidade não aceitos pela pessoa.

Em seus estudos sobre iniciativa, o comentador lembra que, ainda que não se tenha o costume de se vislumbrar iniciativa como agressão, como pronunciaram Perls, Hefferline e Goodman (1951/1997), ao se tomar a agressão como a energia de ação observa-se a iniciativa como uma força trazendo algo para uma interação, podendo ser inclusiva ou exclusiva, unificadora ou segregadora, gratificante e eficaz ou frustrante e ineficaz, dependendo de como ela foi conectada à responsividade/responsabilidade.

Já sobre assertividade, Lichtenberg (2012) considera que esta refere-se a afirmar com segurança, confiança ou força; ser assertivo é também ser agressivo. Aponta ainda que Staemmler teria observado duas concepções de Laura Perls de agressão (as variantes positivas e negativas) como pertencentes a dois sistemas motivacionais diferentes. Assim, menciona a diferença entre "necessidade de exploração e afirmação" e "necessidade de reagir aversivamente através de antagonismo ou retirada (ou ambos)", Porém, segundo Lichtenberg (2012), se aplicar a ideia de ambiguidade universal de Angyal neste contexto, os dois sistemas motivacionais podem estar localizados dentro das Gestalten saudável e neurótica. Deste modo, a visão de Laura Perls de agressão comporta tanto a agressão dentro de uma Gestalt saudável quanto a agressão dentro de uma Gestalt neurótica; ao passo 
que a visão de Staemmler e Joseph Lichtenberg de dois sistemas motivacionais simplesmente divide o problema em agressão (Gestalt neurótica) e exploração-afirmação (Gestalt saudável).

Lichtenberg reconhece que, por um lado, a assertividade não tem a conotação de diminuir ou negar o outro, como a agressividade é muitas vezes (falsamente) acusada de ter, pois é geralmente concebida como agressão exclusiva. Por outro lado, assertividade se refere apenas ao "Eu" do contato e omite qualquer atenção para o outro. Ser agressivo é apoiar o outro a tornar-se uma figura distinta, tanto quanto sugere uma apresentação energética de si. Em vez de diminuir o outro, agressão inclusiva promove a individualização e clareza do outro. Assertividade poderia fazer isso também, mas então teria que ser redefinida como assertividade inclusiva e pouco se ganharia sobre o uso de "agressão".

Assim, colocando em um contexto relacional, a raiva expressa seria bem diferente se: 1) $\mathrm{O}$ ofendido enfatizar apenas as origens de percepção de sua raiva, a sua ação; e 2) O ofendido der igual peso para a sua própria contribuição ao seu sentimento de raiva. Quando alguém é objeto de agressão, esta é experienciada pela pessoa de forma bastante diferente se a agressão é de caráter inclusivo ou exclusivo, e a pessoa também administra a agressão de forma diferente se ela carrega uma Gestalt saudável ou neurótica para o relacionamento. Em terapia, o desafio é experimentar plenamente o impacto das ações do agressor para discriminar o que é a sua própria contribuição para a agressão sentida e para o desamparo, e o que está sendo projetado pelo agressor (Lichtenberg, 2012).

$$
\text { Por fim, Lobb (2015) também }
$$
depõe a favor de Perls ao dizer que a força espontânea, positiva e agressiva tem função de sobrevivência e de interligação social. Em GT, fala-se de "intencionalidade de contato" e, ao fazê-lo, considera-se tanto a força fisiológica "agressiva" que acompanha o movimento de ir ao outro, quanto a evidência do ser-aícom, a fisiologia constitutivamente relacional do ser humano.

\section{Considerações Finais}

As discussões apresentadas demonstram que não há unanimidade quanto à compreensão da proposta perlsiana da teoria da agressão. De um modo geral, a maioria dos comentadores alega entender e apoiar a ideia da agressão dental enquanto uma função biológica necessária à manutenção organísmica, fundamental para o crescimento do organismo e para a interação organismo/meio. Nesse sentido, 
corroboram com o papel positivo da agressão no contato, no manejo de conflitos, na assimilação do novo e na discriminação do conteúdo nutritivo do meio. No entanto, o debate envereda para a agressão hostil e se mantém na seara da análise da positividade e da negatividade desta. A maior parte dos comentadores igualmente acompanha o entendimento de Fritz de que a agressão hostil é do mesmo modo produto da natureza e tem uma importante função na equilibração organísmica, podendo ter um viés positivo nesse processo de preservação do ser e de contato com o meio, e um viés negativo, quando prejudicial a si ou a outrem. Nesse compasso, a agressão dental acaba sendo deixada um pouco de lado.

No geral, portanto, o tema ainda foi pouco estudado e permanece indefinido. Não foram encontrados estudos que procuraram refutar ou confirmar a teoria da agressão dental, a partir do acompanhamento do desenvolvimento de crianças e a relação (ou não) deste com o desenvolvimento dentário, o que poderia encerrar a questão. No que tange à agressão no sentido de hostilidade, os comentadores apresentam estudos que "comprovam" tanto que a agressão hostil não tem função positiva alguma e pode progredir se não for impedida, quanto que apontam para uma função positiva de sua expressão, especialmente seu papel no contato com o outro e o quanto de autoconhecimento a conscientização do uso da agressão pode trazer. Apenas Staemmler (2009) se posicionou completamente contra as duas formas de agressão. Porém, não aponta nenhuma pesquisa que tenha acompanhado crianças ao longo de sua maturação para avaliar a influência do desenvolvimento dentário nelas, apenas menciona que as pesquisas do desenvolvimento não acolhem a teoria, sem dizer que tipo de pesquisas são essas.

Nesse cenário, se se tomar os entendimentos de Ribeiro (2006) e Lichtenberg (2012), pode-se considerar que há um fundo de agressividade em qualquer atividade humana, mesmo na motivação de exploração e de assertividade, pois não há relação sem agressão, já que esta promove o encontro, o que também se depreende dos pressupostos de Perls. Mas, no caso deste, fica difícil definir qual das duas agressões compõe este fundo, embora pareça referirse à agressão dental, já que a toma como função biológica, base da iniciativa de ida ao mundo. Ainda que Ribeiro diferencie agressividade de agressão, ambas as concepções precisam ser melhor clarificadas na GT. Com isso, do ponto de vista clínico, permanece a dúvida sobre se se deve frustrar ou não a expressão 
agressiva do cliente. Considerando-se que a catarse foi criticada na literatura estrangeira analisada, caberia uma revisão de sua utilização na GT brasileira.

Por fim, a diferenciação do significado de raiva, ódio, fúria e agressão permanece pouco estabelecida; bem como a relação de ambas as agressões segue pouco clara, posto que foi abalizada somente por Staemmler (2009) - Yontef (2015) explorou essa relação apenas minimamente - , que optaria por jogar fora toda a teoria da agressão dental e, com isso, desfazer o laço entre elas. Verificouse, assim, um certo avanço na discussão teórica do conceito somente na GT estrangeira. No Brasil, pesquisas como a que ora apresentamos podem abrir novos horizontes e proporcionar revisões da teoria, bem como oferecer mais lógica à prática, principalmente considerando os avanços na lida com a agressão hostil e com o método catártico, agora posto em xeque. Todos os comentadores americanos apresentam formas de manejo alternativas que devem ser consideradas.

\section{Referências}

Bernard, J. M. (1986). Laura Perls: from ground to figure. Life Lines. Journal of Counseling and Development. February, 64, 367-373.

Faria, N. J. (2005). Gestalt-Terapia, Subjetividade e Cultura. Em Holanda, A. F. \& Faria, N. J. (Orgs.). Gestalt-terapia e Contemporaneidade: contribuições para uma construção epistemológica da teoria e da prática gestáltica. (p. 57-82). Campinas: Livro Pleno.

Fittipaldi, A. Q. (2007). Construindo uma cultura de paz: a abordagem gestáltica como um instrumento. 123f. Dissertação (Mestrado em Psicologia) - Universidade de Brasília, Brasília.

Frazão, L.M. \& Fukumitsu, K.O. (2014). Gestalt-Terapia. Conceitos Fundamentais. São Paulo: Summus.

From, I. \& Miller, M. V. (1997). Introdução à edição do The Gestalt Journal. Em Perls, F. S.; Hefferline, R.; Goodman, P. (1951/1997). Gestalt-terapia. São Paulo: Summus.

Helou, F. (2013). Frederick Perls, inquietações e travessias: da Psicanálise à Gestalt-terapia. 144f. Dissertação (Mestrado em Psicologia Clínica e Cultura) - Universidade de Brasília, Brasília.

Helou, F. (2015). Frederick Perls, vida e obra: em busca da Gestalt-terapia. São Paulo: Summus, 2015. 
Holanda, A. F. (2005). Elementos de epistemologia da Gestalt-terapia. Em Holanda, A. F.; Faria, N. J. (Orgs.). Gestalt-terapia e Contemporaneidade: contribuições para uma construção epistemológica da teoria e da prática gestáltica. (p. 23-55). Campinas: Livro Pleno.

Holanda, A. F. (2009). Gestalt-terapia e abordagem gestáltica no Brasil: análise de mestrados e doutorados (1982-2008). Estudos e Pesquisas em Psicologia, UERJ, RJ, ano 9, 1, 98123. Em http://www.revispsi.uerj.br/v9n1/artigos/pdf/v9n1a09.pdf. DOI: 10.12957/epp.2009.9138.

Holanda, A. F. \& Karwowski, S. L. (2004). Produção Acadêmica em Gestalt-terapia no Brasil: análise de Mestrados e Doutorados. Psicologia, Ciência e Profissão, 24(2), 60-71. DOI: $10.1590 / \mathrm{S} 1414-98932004000200008$.

Lichtenberg, P. (2012). Inclusive and Exclusive Aggression: Some (Gestalt) Reflections. Gestalt Review, 16(2), 145-161.

Lobb, M. S. (2015). Fundamentals and development of Gestalt Therapy in the contemporary context. Gestalt Review, 19(2), 1-24.

Loffredo, A. M. (1992). De cotovelos apoiados no para-peito da palavra: no cenário clínico, qual é o horizonte? 264f. Tese (Doutorado em Psicologia) - Universidade de São Paulo, São Paulo.

Müller-Granzotto, M. J.; Müller-Granzotto, R. L. (2007). Perls leitor de Freud, Goldstein e Friedlander e os primeiros ensaios em direção a uma psicoterapia gestáltica. Estudos $e$ Pesquisas em Psicologia, 7(1), 42-55.

Perls, F. S. (2002). Ego, Fome e Agressão: uma revisão da teoria e do método de Freud. São Paulo: Summus. (Original em 1942).

Perls, F. S. (1979). Escarafunchando Fritz: dentro e fora da lata de lixo. São Paulo: Summus. (Original em 1969).

Perls, F. S. (2011). A abordagem gestáltica e testemunha ocular da terapia. Rio de Janeiro: LTC. (Original em 1973).

Perls, F. S. (1977). Moral, Fronteira do Ego e Agressão. Em Stevens, J. O. (org.). Isto é Gestalt. (p. 49-61). São Paulo: Summus. (Original em 1975).

Perls, F. S.; Hefferline, R.; Goodman, P. (1997). Gestalt-terapia. São Paulo: Summus. (Original em 1951).

Perls, L. (1988). A conversation with Laura Perls. Em J. Wysong e E. Rosenfeld (Orgs.), An oral history of Gestalt Therapy: interviews with Laura Perls, Isadore From, Erving 
Polster, Miriam Polster, Elliot Shapiro. (p.3-25). Gouldsboro, Maine, USA: The Gestalt Journal Press.

Perls, L. (1994). Vivendo en los límites. Valência: Promolibro. (Original em 1992).

Pimentel, A. (2005). Nutrição Psicológica: desenvolvimento emocional infantil. São Paulo: Summus.

Ranaldi, C. (2007). Agressão. Em Gladys D’Acri, Patrícia Lima \& Sheila Orgler (Orgs.). Dicionário de Gestalt-Terapia. “Gestaltês” (p. 19-20). São Paulo: Summus.

Ribeiro, J. P. (2005). A natureza epistemológica da abordagem gestáltica: Gestalt-terapia como processo. Em Holanda, A. F.; Faria, N. J. (Orgs.). Gestalt-terapia e Contemporaneidade: contribuições para uma construção epistemológica da teoria e da prática gestáltica. (p. 145-169). Campinas: Livro Pleno.

Ribeiro, J. P. (2006). Vademecum de Gestalt-terapia: conceitos básicos. São Paulo: Summus.

Skovgaard, R.; Winther-Jensen, L. (2015). The Question of Anger: on Frank and Barbara Staemmler's critique of Perls. Gestalt Review, 19(3), 196-211.

Smith, E. W. L. (2007). Gestalt Therapy and the Concretization of Nietzsche's Metaphor. Gestalt Review, 11(3), 207-216.

Staemmler, B. \& Staemmler, F-M. (2015). Aggression or Self-Assertion? Response to Skovgaard and Winther-Jensen. Gestalt Review, 19(3), 212-219.

Staemmler, F-M. (2009). Aggression, Time, and Understanding: contributions to the evolution of Gestalt Therapy. New York: Routledge.

Yontef, G. (2015). Considering Anger and Aggression: response to Skovgaard and WintherJensen. Gestalt Review, 19(3), 220-223.

\section{Os autores:}

Thauana Santos de Araújo é mestre em Psicologia pela Universidade Federal do Paraná; Graduada em Psicologia pela Universidade Tuiuti do Paraná (2014) e em Direito pela Pontifícia Universidade Católica do Paraná (2010). Atualmente, é Professora nas Faculdades FACEL e trabalha também como psicóloga clínica (CRP-08/20667). Membro do Laboratório de Fenomenologia e Subjetividade/UFPR. Email: thauanaaraujo@ hotmail.com

Adriano Furtado Holanda é psicólogo, mestre e doutor em Psicologia, docente do Programa de Pós-Graduação e Graduação em Psicologia da Universidade Federal do Paraná, Coordenador do Laboratório de Fenomenologia e Subjetividade (LabFeno/UFPR). Contato: www.labfenoufpr.com.br / aholanda@yahoo.com

Recebido em: 21/03/2017.

Aprovado em: 16/06/2017. 